\title{
ANATOMIA DA MADEIRA DE TERNSTROEMIA BRASILIENSIS CAMBESS. (PENTAPHYLACACEAE) ${ }^{1}$
}

\author{
JOÃO CARLOS FERREIRA DE MELO JÚNIOR ${ }^{2}$ MAICK WILLIAN AMORIM ${ }^{3}$ \\ ÍGOR ABBA ARRIOLA ${ }^{4}$
}

\section{RESUMO}

O presente estudo descreve e ilustra a anatomia do lenho de Ternstroemia brasiliensis (Pentaphylacaceae) a partir de coletas realizadas em ambiente de restinga no estado de Santa Catarina, Brasil. Os caracteres anatômicos mais representativos são: vasos de pequeno diâmetro e elevada frequência, espessamentos espiralados presentes em elementos de vaso, traqueídes vasicêntricos, placas de perfuração escalariformes, parênquima axial apotraqueal difuso e raios heterogêneos extremamente altos. A conjunção destes caracteres indica primitividade ao lenho desta espécie.

Palavras-chave: anatomia do lenho, Pentaphylacaceae, Ternstroemia brasiliensis.

\section{ABSTRACT}

[Wood anatomy of Ternstroemia brasiliensis Cambess. (Pentaphylacaceae)].

This study describe and illustrate the wood anatomy of Ternstroemia brasiliensis (Pentaphylacaceae) from samples collected in a sandbank environment in the state of Santa Catarina, Brazil. The most representative anatomical features are: small vessel diameter and high vessel frequency, helical thickenings in vessel elements, vasicentric tracheids present, scalariform perforation plates, apotracheal diffuse axial parenchyma and extremely high heterogeneous rays. The conjunction of these features indicates a high primitiveness to this wood species.

Keywords: Pentaphylacaceae, Ternstroemia brasiliensis, wood anatomy.

\section{INTRODUÇÃO E REVISÃO DE LITERATU- RA}

A família Pentaphylacaceae, anteriormente considerada monogenérica (Cronquist, 1981), abriga, atualmente, 14 gêneros distribuídos pela Ásia, África, ilhas do Pacífico e Américas Central e do Sul (Weitzman et al., 2004). Tais gêneros estão organizados em quatro tribos: Sladenieae (Sladenia e Ficalhoa), Pentaphylaceae (Pentaphylax), Ternstroemieae

1 Recebido em 29-9-2016 e aceito para publicação em 2710-2016.

2 Biólogo, Doutor, Professor Titular do Departamento de Ciências Biológicas, Laboratório de Anatomia e Ecologia Vegetal, Universidade da Região de Joinville, Joinville, Santa Catarina, Brasil. joao.melo@univille.br

3 Acadêmico, curso de Ciências Biológicas - Meio Ambiente e Biodiversidade, Departamento de Ciências Biológicas, Universidade da Região de Joinville, Joinville, Santa Catarina, Brasil. maickwamorim@gmail.com

4 Acadêmico, curso de Ciências Biológicas - Meio Ambiente e Biodiversidade, Departamento de Ciências Biológicas, Universidade da Região de Joinville, Joinville, Santa Catarina, Brasil. arriolaigor@gmail.com
(Ternstroemia e Anneslea) e Freziereae (Adinandra, Archboldiodendron, Eurya, Freziera, Symplococarpon, Euryodendron, Visnea e Balthasaria) (Tsou, 2016).

Até o sistema de classificação APG (1998), a maior parte dos gêneros que compõem a atual família Pentaphylacaceae estava circunscrita sob outros taxa que, por um grande período, permaneceram majoritariamente agrupados junto à família Theaceae, por compartilharem características morfológicas como segmentos de perianto imbricado e deiscência longitudinal das anteras (Every, 2009). Posteriormente, revisões filogenéticas baseadas em sequenciamento molecular serviram para reorganizá-los em uma subfamília (Ternstroemioideae) e três tribos: Pentaphylaceae, Ternstroemieae e Freziereae (Prince \& Parks, 2001). Recentemente, por meio de novos sequenciamentos de DNA, a família tomou a sua atual organização com quatro tribos, agrupando também os gêneros da antiga família Sladeniaceae (Tsou, 2016). 
Globalmente, a família abrange cerca de 340 espécies, sendo que aproximadamente 130 ocorrem na região Neotropical, com destaque aos gêneros Ternstroemia (60 spp.), Freziera (42 spp.), Cleyera (16 spp.) e Symplocarpon (9 spp.) (Temponi, 2004; Every, 2009). No Brasil, a família é representada apenas pelos gêneros Ternstroemia (19 spp.) e Freziera (1 sp.), totalizando 20 espécies distribuídas em 17 estados, das quais 12 são endêmicas (Sobral \& Bittrich, 2015). Ternstroemia é o gênero mais rico da família, com cerca de 100 espécies distribuídas na América, África, leste e sudeste da Ásia; a maior parte das mesmas encontra-se na América do Sul, que é o centro de diversidade do gênero (Weitzman et al., 2004; Every, 2009; Aguilar et al., 2015).

Nos três estados da região Sul do Brasil, registra-se, apenas, a ocorrência de Ternstroemia brasiliensis Cambess., espécie que também é encontrada no Sudeste (São Paulo, Rio de Janeiro, Minas Gerais) e Nordeste do país (Bahia e Sergipe). Trata-se de espécie endêmica do Brasil e a Pentaphylacaceae com maior distribuição geográfica no país (Sobral \& Bittrich, 2015).

Ternstroemia brasiliensis, também conhecida pelo nome vernacular "pinta-noiva", ocorre em solos bem drenados de florestas de altitude e planícies litorâneas (Pires et al., 2009; Souza \& Lorenzi, 2012). Em fitofisionomias de restinga da região Sul e Sudeste, apresenta grande importância fitossociológica, ocorrendo como espécie secundária ou pioneira antrópica em florestas secundárias da planície quaternária (Sugiyama, 1998; Salimon \& Negrelle, 2001; Melo Júnior \& Boeger, 2015).

A espécie é descrita como uma árvore perene de até $7 \mathrm{~m}$ de altura e $12 \mathrm{~cm}$ de diâmetro do caule à altura do peito. $\mathrm{O}$ caule possui casca interna rósea, com estrias creme. A filotaxia é alterna, com folhas simples, inteiras, coriáceas, glabras em ambas as faces, de 7-15 cm de comprimento e 3,5-6,5 de largura, com nervuras pouco visíveis e pontoações pretas na face abaxial. As flores são monoclinas, solitárias e de cor rósea. O fruto, do tipo baga, é globoso, achatado e com arilo vermelho (Sampaio et al., 2005).

Embora ecologicamente importante, sobretudo como fornecedora de recursos à avifauna, que é atraída pela cor vermelha do arilo das sementes (Souza \& Lorenzi, 2012), a espécie ainda é pouco estudada. Na bibliografia encontramse estudos sobre a germinação das sementes de T. brasiliensis (Pires et al., 2009), bem como estudos comparativos entre a morfologia e a nutrição foliar de espécies arbóreas em ambientes florestais (Boeger \& Wisnewski, 2003; Boeger et al., 2005; Boeger et al., 2016). Estudos anatômico-descritivos da madeira ainda inexistem na literatura científica, incluindo as bases de dados mundiais (Wheeller, 2011).

Neste sentido, o objetivo deste estudo é caracterizar a anatomia da madeira de Ternstroemia brasiliensis, com vistas a contribuir para a ampliação dos conhecimentos sobre esta espécie.

\section{MATERIAL E MÉTODOS}

O material botânico estudado é procedente da formação arbustivo-arbórea de um remanescente de restinga com 6.667 ha de área, localizado na planície costeira da região nordeste do estado de Santa Catarina (coordenadas $26^{\circ} 17^{\prime} \mathrm{S}$ e 48 33'W). O clima, caracterizado como Cfa segundo a classificação de Köppen, é mesotérmico, fortemente influenciado pela umidade marítima, sem estação seca definida e com verões quentes. A precipitação média anual é de $1.874 \mathrm{~mm}$ (Knie, 2002). A temperatura média anual é de $21,3^{\circ} \mathrm{C}$. A formação arbustivaarbórea desta restinga compõe-se de arbustos e árvores de 2-5m de altura e apresenta solo do tipo Espodossolo Ferrihumilúvico não hidromórfico (Silva et al., 2016).

Amostras de madeira foram coletadas à altura do peito de cinco indivíduos amostrais de Ternstroemia brasiliensis (Pentaphylacaceae) para a preparação de lâminas histológicas permanentes. Corpos de prova foram confeccionados para o cozimento em água glicerinada e 
posterior secsagem em micrótomo de deslize Zeiss, com navalha tipo $\mathrm{C}$, nos planos transversal, longitudinal radial e longitudinal tangencial (Johansen, 1940; Sass, 1951). Em seguida, os cortes foram clarificados em hipoclorito de sódio, lavados em água destilada, corados com safrablau, desidratados em série etílica crescente (Kraus \& Arduin, 1997) e montados em resina sintética do tipo verniz vitral (Paiva et al., 2006). Material dissociado foi obtido pela imersão de corpos de prova em solução de Franklin aquecida a $60^{\circ} \mathrm{C}$ (Kraus \& Arduin, 1997), para posterior biometria de vasos (comprimento e diâmetro tangencial) e fibras (comprimento e espessura da parede), com $n=30$. As microfotografias foram capturadas com fotomicroscópio Olympus CX-31. As mensurações foram feitas por meio do software Dino Eye 2.0. A caracterização anatômica foi baseada na terminologia do IAWA Committee (1989).

\section{RESULTADOS}

A caracterização anatômica da madeira de Ternstroemia brasiliensis é abaixo descrita e ilustrada (Figura 1).

Camadas de crescimento: distintas, demarcadas por espessamento radial das paredes das fibras no lenho tardio.

Vasos: porosidade difusa, sem arranjo definido; solitários e múltiplos radiais de 2-9, múltiplos tangenciais de 2-3, raros racemiformes; diâmetro tangencial de 34,78 - 97,22 $\mu \mathrm{m}(55,94$ $\pm 16,22$ ); espessamentos helicoidais, presentes em elementos de vaso mais estreitos; frequência de 73 - $121(97,3 \pm 4,24)$ vasos $/ \mathrm{mm}^{2}$; comprimento de 910 - $1800 \mu \mathrm{m}$ (1359 \pm 629$)$; placas de perfuração escalariformes com 20-40 barras; pontoações intervasculares opostas, areoladas, pequenas de 3,04 - 4,01 $\mu \mathrm{m}(3,55 \pm 0,27)$; pontoações radio-vasculares, semelhantes às intervasculares; traqueídes vasicêntricos, presentes.

Fibras: libriformes; não septadas; comprimento de 487 - $709 \mu \mathrm{m}(613 \pm 55,56)$; largura de 20,8 - 24,9 $\mu \mathrm{m}(22,6 \pm 1,33)$; pontoações sim- ples a diminutas areoladas (vista longitudinal tangencial); espessura da parede de fibras, de fina a espessa.

Parênquima axial: apotraqueal difuso; difuso em agregados; paratraqueal escasso; séries parenquimáticas compostas por 5 células.

Raios: unisseriados e 5 - 9 seriados $(7,27 \pm$ 1,08); largura de 62 - $117 \mu \mathrm{m}(90 \pm 11,05)$; heterogêneos, com corpo formado por células procumbentes, quadradas e eretas, misturadas ao longo de raios extremamente altos.

\section{DISCUSSÃO}

As camadas de crescimento observadas nos espécimes aqui estudados são evidenciadas pela ocorrência de fibras com paredes celulares radialmente mais espessas no lenho tardio, com redução abrupta para o lenho inicial. A presença de anéis de crescimento é uma característica variável nas espécies de sua antiga circunscrição (Theaceae), sendo pouco definidos ou ausentes (Record \& Hess, 1943), enquanto outras espécies apresentam anéis semi-porosos (Metcalfe \& Chalk, 1957). A presença de camadas de crescimento é relatada como um caráter comum em $48 \%$ das espécies de clima tropical (Alves \& Angyalossy, 2000) e está condicionada a fatores ambientais sazonais que influenciam na atividade do câmbio vascular (Lisi et al., 2008; Giraldo-Jiménez, 2011). Dentre os fatores que influenciam a atividade cambial destacam-se a pluviosidade e a temperatura (Tomazello Filho et al., 2001), o que pode explicar a demarcação das camadas de crescimento nos espécimes estudados.

Características como vasos geralmente solitários, de pequeno diâmetro tangencial e elevada frequência, observadas em Ternstroemia brasiliensis, se aproximam, do ponto de vista quantitativo, à caracterização das madeiras de Ternstroemiaceae (Pentaphylacaceae), as quais apresentam vasos em sua maioria solitários e com diâmetro tangencial de 30-95 $\mu \mathrm{m}$ (Stevens et al., 2004). A elevada frequência (16-400 vasos $/ \mathrm{mm}^{2}$ ), também observada neste estudo, corrobora o descrito para madeiras de Theaceae 

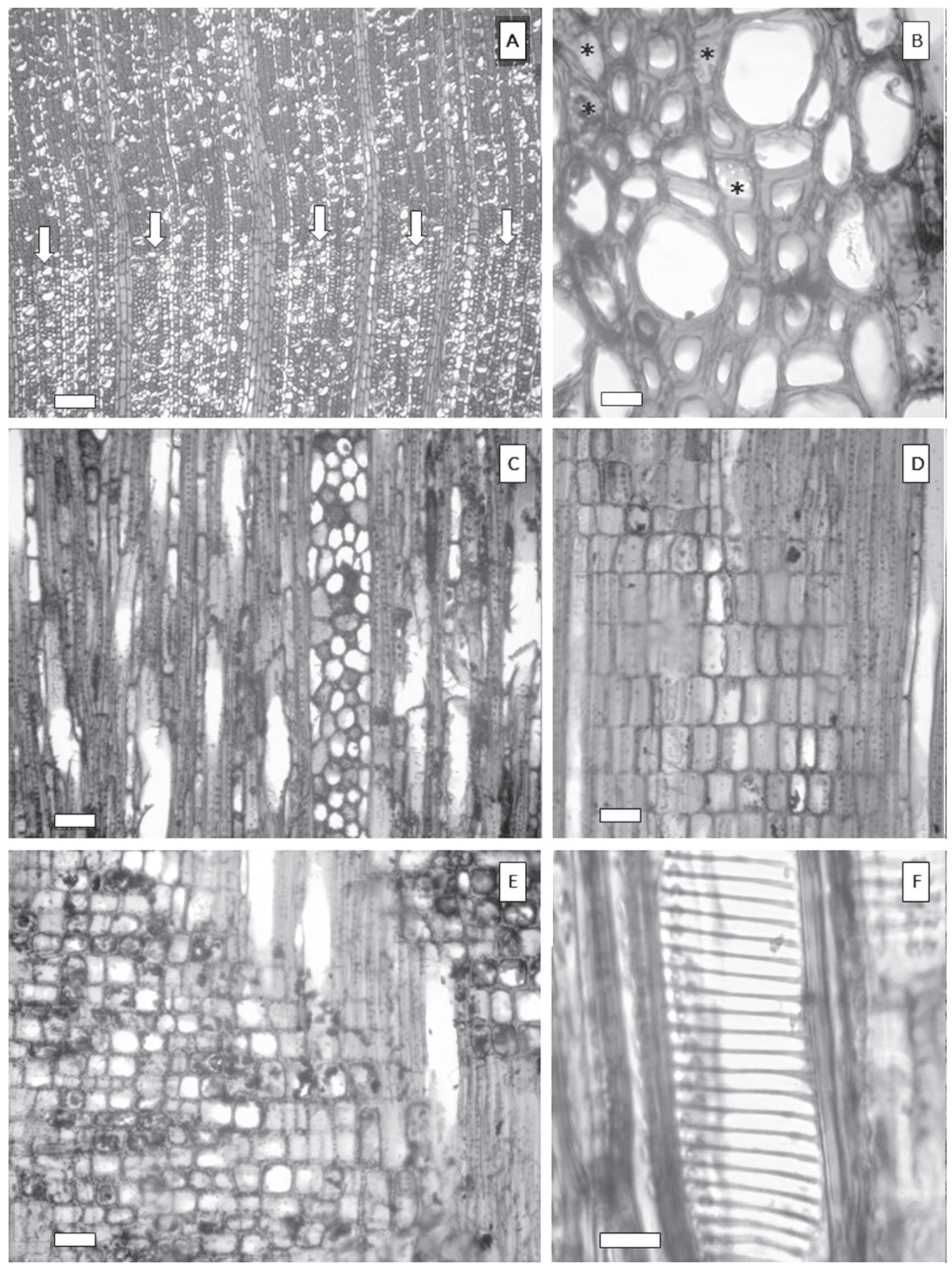

FIGURA 1 - Anatomia da madeira de Ternstroemia brasiliensis (Pentaphylacaceae). A - Camada de crescimento distinta (setas) e porosidade difusa, em secção transversal. B - Parênquima apotraqueal difuso (*), em secção transversal. C - Raio multisseriado extremamente alto, em secção longitudinal tangencial. D - Raio heterogêneo, composto por células eretas e quadradas, em secção longitudinal radial. E - Raio heterogêneo, composto por células procumbentes, eretas e quadradas, misturadas em secção longitudinal radial. F - Placa de perfuração escalariforme. Barras de escala $=$ $200 \mu \mathrm{m}(\mathrm{A}-\mathrm{E})$. Barra de escala $=50 \mu \mathrm{m}(\mathrm{F})$. 
(Weitzman et al., 2004). A porosidade difusa é apontada como presente na maioria das espécies de clima tropical (IAWA, 1989), caso das espécies de Theaceae e Pentaphylacaceae (Stevens et al., 2004, Weitzman et al., 2004). Já os vasos em múltiplos radiais, também presentes em T. brasiliensis, têm, em relação aos solitários, maior capacidade de condução de água no xilema, por apresentarem maior área transversal e difusão lateral através das pontoações (Carlquist, 1984; Baas, 1982). Placas de perfuração escalariformes, características de elementos de vasos primitivos muito próximos a traqueídes (Cutler et al., 2011), são reportadas para as espécies de Theaceae e Ternstroemiaceae (Stevens et al., 2004, Weitzman et al., 2004) e citados como comuns no gênero Ternstroemia (Record \& Hess, 1943; Metcalfe \& Chalk, 1957), mas podem tornar o xilema mais suscetível a embolias em ambientes com deficiência hídrica no solo (Wheeler \& Baas, 1991).

Alves \& Angyalossy (2000) observaram, num total de 491 espécies de 133 famílias de plantas tropicais, uma frequência de apenas $2 \%$ de espécies com espessamentos espiralados em elementos de vaso, sugerindo a presença mais comum em plantas de regiões temperadas. Os espessamentos espiralados conferem maior segurança e eficiência na condução de água no xilema secundário, além de resistência à seca nos diferentes taxa (Carlquist \& Hoekman, 1985; Baas \& Carlquist, 1985; Lindorf, 1994). Em condição de estresse hídrico, este tipo de espessamento pode manter o lúmen da célula condutora aberto, mesmo quando as células parenquimáticas estão murchas, evitando a embolia (Mauseth et al., 1995).

A presença de traqueídes vasicêntricas pode ser considerada uma estratégia associada a outras características do lenho, com vistas a aumentar a segurança no transporte hídrico (Carlquist, 1988). Carlquist (1985), em estudo sobre a flora do sul da Califórnia e áreas similares, encontrou, em diversas espécies, maior presença de traqueídes vasicêntricas no lenho de plantas em áreas com baixa disponibilidade de água. Desta forma, a presença de traqueídes vasicêntricos em Ternstroemia brasiliensis pode ser considerada uma estratégia para assegurar o transporte hídrico no solo de restinga.

O gênero Ternstroemia apresenta parênquima axial apotraqueal difuso (Metcalfe \& Chalk, 1957; Weitzman et al., 2004); cita-se, ainda, a ocorrência de parênquima paratraqueal (Herat \& Theobald, 1977), caráter também observado no presente estudo. O parênquima axial apotraqueal difuso, considerado primitivo (León \& Pernia, 1999), juntamente com outras estruturas observadas em Ternstroemia brasiliensis, tais como placas de perfuração escalariformes, revelam uma junção de caracteres primitivos. Os raios multisseriados, heterogêneos e extremamente altos, presentemente observados, corroboram referências para o gênero Ternstroemia, feitas por Record \& Hess (1949) e Metcalfe \& Chalk (1957), mas diferem daquela feita por Stevens et al. (2004), que descreve o mesmo como tendo raios da mesma altura. Raios compostos por diferentes tipos celulares compreendem uma condição filogenética primitiva, em que as células eretas não são maximamente eficazes no transporte de fotoassimilados e representam uma transição histológica entre os parênquimas axial e radial (Carlquist, 2001).

\section{REFERÊNCIAS BIBLIOGRÁFICAS}

AGUILAR, D.S.; JÍMENEZ-MADRIGAL, J.; MONRO, A.K. A new species of Ternstroemia (Pentaphylacaceae) from La Amistad Binational Park and World Heritage Property, Costa Rica and Panama. Phytotaxa, v. 217, n. 1, p. 87-91, 2015.

ALVES, E.S.; ANGYALOSSY-ALFONSO, V. Ecological trends in the wood anatomy of some Brazilian species. I: Growth rings and vessels. IAWA Journal, v. 21, p. 3-30, 2000.

APG. An ordinal classification for the families of flowering plants. Annals of the Missouri Botanical Garden, n. 85, p. 531-553, 1998.

BAAS, P. Systematic, phylogenetic, and ecological wood anatomy - History and perspectives. In: P. Baas (ed.). New perspectives in wood anatomy. 
The Hague: Junk, Nijhoff \& Hingham, 1982. p. 23-58.

BAAS, P.; CARLQUIST, S. A comparison of the ecological wood anatomy of the floras of southern California and Israel. IAWA Bulletin, Utrecht, v. 6, n. 4, p. 349-353, 1985.

BOEGER, M.R.T.; WISNIEWSKI, C. Comparação da morfologia foliar de espécies arbóreas de três estádios sucessionais distintos de floresta ombrófila densa (Floresta Atlântica) no Sul do Brasil. Revista Brasileira de Botânica, v. 26, n. 1, p. 61-72, 2003.

BOEGER, M.R.T; WISNIEWSKI, C.; REISSMANN, C.B. Nutrientes foliares de espécies arbóreas de três estádios sucessionais de floresta ombrófila densa no sul do Brasil. Acta Botânica Brasilica, v. 19, n. 1, p. 167-181, 2005.

BOEGER, M.R.T.; SILVA, M.M.; NOGUEIRA, G.; ALVARENGA, A.; PERETO, S.S. Occurrence of homobaric and heterobaric leaves in two forest types of southern Brazil. Acta Botanica Brasilica, v. 30, n. 2, p. 304-312, 2016.

CARLQUIST, S.; HOEKMAN, D.A. Ecological wood anatomy of the woody southern Californian flora. IAWA Bulletin, Utrecht, v. 6, n. 4, p. 319-347, 1985.

CARLQUIST, S. Vasicentric tracheids as a drought survival mechanism in the woody flora of southern California and similar regions: review of vasicentric tracheids. Aliso, n. 11, p. 37-68, 1985.

CARLQUIST, S. Vessel grouping in Dicotyledon wood: significance and relationship to imperforate tracheary elements. Aliso, n. 10, p. 505-525, 1984.

CARLQUIST, S. Comparative wood anatomy: systematic, ecological and evolutionary aspects of Dicotyledon woods. Berlin: Springer-Verlag, 1988.

CARLQUIST, S. Comparative wood anatomy: systematic, ecological, and evolutionary aspects of Dicotyledon woods. New York: Springer; 2001.

CRONQUIST, A. An integrated system classification of flowering plants. New York: Columbia University Press, 1981.

CUTLER, F.D.; BOTHA, T.; STEVENSON D.W. Anatomia Vegetal. Uma abordagem aplicada. Artemed, 2011.

EVERY, J.L.R. Neotropical Pentaphylacaceae. In: Milliken, W., Klitgård, B. \& Baracat, A. (2009 onwards), Neotropikey - Interactive key and information resources for flowering plants of the Neotropics. 2009.

GIRALDO-JIMÉNEZ, J.A. Dendrocronología en el trópico: aplicaciones actuales y potenciales. Colombia Forestal, v. 14, n. 1, p. 97-111, 2011.

HERAT, T.S.; THEOBALD, W.L. Comparative studies of vegetative anatomy in the Theaceae of Sri Lanka. Botanical Journal of the Linnean Society, v. 75, p. 375-386, 1977.

IAWA Committee. List of microscopic features for hardwood identification. IAWA Bulletin, v. 10, p. 219-332, 1989.

JOHANSEN, D.A. Plant microtechnique. London: McGraw-Hill, 1940.

KNIE, J.L.W. (org.). Atlas ambiental da região de Joinville: complexo hídrico da Baía da Babitonga. FATMA/GTZ, Florianópolis, 2002.

KRAUS, J.E.; ARDUIN, M. Manual básico de métodos em morfologia vegetal. Rio de Janeiro: EDUR, 1997. 198 p.

LEÓN, W.; PERNÍA, N. Variabilidad de la madera de Cordia thaisiana Agostini (Boraginaceae) en sentido longitudinal. Revista Forestal Venezolana, v. 43, n. 1, p. 33-42, 1999.

LINDORF, H. Eco-anatomical wood features of species from a very dry tropical forest. IAWA Journal, Leuven, v. 15, n. 4, p. 61-376, 1994.

LISI, C.S.; TOMAZELLO-FILHO, M.; BOTOSSO, P.C.; ROIG, F.A.; MARIA, V.R.B.; FERREIRAFEDELE, L.; VOIGT, A.R.A. Tree-ring formation, radial increment periodicity and phenology of tree species from a Seasonal SemiDeciduous Forest in Southeast Brazil. IAWA Journal, n. 29, p. 189-207, 2008.

MAUSETH, J.D.; UOZUMI, Y.; PLEMONS, B.J.; LANDRUM, J.V. Structural and systematic study of an unusual tracheid type in cacti. Journal of Plant Research, n. 108, p. 517-526, 1995.

MELO JÚNIOR, J.C.F.; BOEGER, M.R.T. Riqueza, estrutura e interações edáficas em um gradiente de restinga do Parque Estadual do Acaraí, Estado de Santa Catarina, Brasil. Hoehnea, v. 42, n. 2, p. 207-232, 2015.

METCALFE, C.R.; CHALK, L. Anatomy of the Dicotyledons. Leaves, stem, and wood, in relation to taxonomy with notes on economic uses. Oxford: Clarendon Press, 1957.

PAIVA, J.G.A.; FANK-DE-CARVALHO, S.M.; MAGALHÃES, M.P.; GRACIANO-RIBEIRO, D. Verniz vitral incolor 500: uma alternativa de 
meio de montagem economicamente viável. Acta Botanica Brasilica, v. 20, n. 2, p. 257-264, 2006.

PIRES, L.A..; CARDOSO, V.J.M..; JOLY, C.A.; RODRIGUES, R.R. Germinação de Ternstroemia brasiliensis Cambess. (Pentaphylacaceae) de floresta de restinga. Acta Botanica Brasilica, v. 23, n. 1, p. 57-66, 2009.

PRINCE, L.M.; PARKS, C.L. Phylogenetic relationships of Theaceae inferred from chloroplast DNA sequence data. American Journal of Botany, v. 88, n. 12, p. 2309-2320, 2001.

RECORD, S.J.; HESS, R.W. Timbers of the New World. New Haven: Yale University Press, 1949. $640 \mathrm{p}$.

SAMPAIO, D.; SOUZA, V.C.; OLIVEIRA, A.A.; PAULA-SOUZA, J.; RODRIGUES, R.R. Árvores da Restinga. São Paulo: Editora Neotrópica, 2005. 277 p.

SALIMON, C.I.; NEGRELLE, R.B. Natural regeneration in a quarternary coastal plain in the southern Brazilian Atlantic Rain Forest. Brazilian Archives of Biology and Technology, n. 44, p. 155-163, 2001.

SASS, J. E. Botanical microtechnique. Ames: Iowa State College Press, 1951. 228 p.

SILVA, K.R.; MELO JÚNIOR, J.C.F.; BOEGER, M.R. Variações fenotípicas em Andira fraxinifolia Benth. (Fabaceae) em duas fitofisionomias de restinga. Hoehnea, v. 43, n. 2, p. 229-237, 2016.

SOBRAL, M.; BITTRICH, V. Pentaphylacaceae. In: Lista de espécies da Flora do Brasil. Rio de Janeiro: Jardim Botânico do Rio de Janeiro, 2016. Disponível em: <http://floradobrasil. jbrj.gov.br/ jabot/floradobrasil/FB12575>.

SOUZA, V.C.; LORENZI, H. Botânica Sistemática: guia ilustrado para identificação das famílias de fanerógamas nativas e exóticas no Brasil, baseado em APG III. Nova Odessa, São Paulo: Instituto Plantarum, 2012.
STEVENS, P.F.; DRESSLER, S.; WEITZMAN, A.L. Ternstroemiaceae. In: KUBITZKI, K. (ed.). The families and genera of vascular plants. VI. Flowering plants. Dicotyledons. Celastrales, Oxalidales, Rosales, Cornales, Ericales. Berlim: Springer, 2004. p 463-471.

SUGYAMA, M. Estudo de florestas da restinga da Ilha do Cardoso, Cananéia, São Paulo, Brasil. Boletim do Instituto de Botânica, n. 11, p. 119159, 1998.

TEMPONI, L.V.; UDULUTSCH, R.G.; KOEHLER, S. Flora da Serra do Cipó, Minas Gerais: Pentaphylacaceae (Ternstroemiaceae). Bol. Bot. Univ. São Paulo, v. 22, n. 1, p. 35-38, 2004.

TOMAZELLO FILHO, M.; BOTOSSO, P.C.; LISI, C.S. Análise e aplicação dos anéis de crescimento em árvores como indicadores ambientais: dendrocronologia e dendroclimatologia. In: MAIA, N.B.; MARTOS, H.L.; BARRELA, W. (Org.). Indicadores Ambientais: conceitos e aplicações. São Paulo: EDUC. 2001. p. 117-143.

TSOU, C.H.; LI, L.; VIJAYAN, K. The intra-familial relationships of Pentaphylacaceae s.l. as revealed by DNA Sequence Analysis. Biochem. Genet., v. 54, n. 3, p. 270-282, 2016.

WEITZMAN, A.L.; DRESSLER, S.; STEVENS, P.F. Ternstroemiaceae. In: KUBITZKI, K. (ed.). The families and genera of vascular plants. VI. Flowering plants. Dicotyledons. Celastrales, Oxalidales, Rosales, Cornales, Ericales. Berlim: Springer, 2004. p. 450-460.

WHEELER, E.A. Insidewood - A web resource for hardwood anatomy. IAWA Journal, v. 32, n. 2, p. 199-211, 2011.

WHEELER, E.A.; BAAS, P. A survey of the fossil record for Dicotiledonous wood and its significance for evolutionary and ecological wood anatomy. IAWA Journal, v. 12, n. 3, p. 275318, 1991. 